\title{
Managing benign tracheal stenosis during COVID-19 outbreak
}

\author{
Silvia Fiorelli ${ }^{1}\left[\right.$ (D) Cecilia Menna ${ }^{2} \cdot$ Domenico Massullo $^{1} \cdot$ Erino Angelo Rendina ${ }^{2}$
}

Received: 26 May 2020 / Accepted: 13 August 2020 / Published online: 26 August 2020

(c) The Japanese Association for Thoracic Surgery 2020

\section{Dear Editor,}

Coronavirus disease 2019 (COVID-19) pandemic, raised up during early 2020 , has been challenging surgery worldwide. If elective surgery has been recommended to be postponed [1], some diseases could potentially become life-threatening and cannot be delayed. Among these conditions, tracheal idiopathic stenosis, primary caused by endotracheal intubation or tracheostomy, usually become symptomatic when reach $50 \%$ obstruction. Although formerly temporary Montgomery T-tube placement and tracheostomy were historically considered possible alternatives to surgery, they are no longer recommended because of the risk of bacterial colonization and extension of the stenotic segment, representing the last resorts. Nowadays surgical resection and tracheal reconstruction are the definitive treatment of choice. Interventional bronchoscopy role, such as mechanical dilatation, laser ablation and stenting, is limited since the recurrences are frequent and usually reserved to palliative endoscopic laser treatment. Endoscopic treatment of complex stenosis extended $>1 \mathrm{~cm}$ and with tracheal wall involvement is contraindicated and, when feasible, surgery should remain the treatment of choice [2]. In fact, mechanical dilation for complex stenoses, leads to a recurrence rate of $>90 \%$. Conversely, considering short and long-term results, the failure rate of surgery is $9 \%$ [3].

On the contrary, during pandemic, interventional endoscopic treatments could have an adjunctive role in tracheal stenosis management. Dilation may represent a bridge to surgery, helping to successfully manage symptomatic

Cecilia Menna

silvia.fiorelli@uniroma1.it

1 Anesthesia and Intensive Care Medicine, Department of Clinical and Surgical Translational Medicine, Sant'Andrea Hospital, Sapienza University of Rome, Via di Grottarossa 1035, 00189 Rome, Italy

2 Thoracic Surgery, Department of Clinical and Surgical Translational Medicine, Sant' Andrea Hospital, Sapienza University of Rome, Rome, Italy patients and delaying surgery. In these population avoiding tracheal stenting is paramount because of its potential tissue damage, exerting friction and radial pressure on the airway wall causing an inflammatory response with granulation and further strictures that can impair subsequent surgical treatment [4]. Endoscopic procedures could be considered as first treatment in selected patients after stenosis evaluation, such as non-complex stenosis with low grade of cartilage involvement or tracheomalacia [5]. Diaphragm or weblike stenoses can be treated by the mucosal sparing technique with a $60 \%$ success rate after $1 \pm 3$ sessions [6].

Since COVID-19 infection transmission from asymptomatic or minimally symptomatic patients to other persons is possible, cross infection risk during tracheal surgery has to be considered even in non-symptomatic patients. Airway surgery and bronchoscopy, are high-risk aerosol-generating procedures (AGPs) and require airborne personal protective equipment (PPE). Tracheal surgery often requires an advanced airway management, challenging anesthesiologists and thoracic surgeons. A complex highly specialized approach is often required. Different tools (fiberoptic bronchoscope, video laryngoscope, laryngoscope) and several devices (supraglottic airway devices, mono and double lumen endotracheal tubes) may be required for a single case [7]. Moreover various techniques to ensure ventilation and gas exchange can be adopted, according to the stenosis level, such as one lung ventilation, jet ventilation, and cross field ventilation [8]. These high-complex procedures can dramatically increase the cross-infection risk for healthcare workers during surgery.

For above mentioned reasons, during pandemic tracheal surgery should be reserved to high-complex stenosis or weblike tracheal stenosis previously treated through "bridge" endoscopic treatment that can be no-longer managed with interventional procedures. 


\section{Compliance with ethical standards}

Conflict of interest The authors have no conflicts of interest to disclose.

\section{References}

1. Brindle EM, Gawande A. Managing COVID-19 in surgical systems. Ann Surg. 2020;272(1):e1-2.

2. Siciliani A, Rendina EA, Ibrahim M. State of the art in tracheal surgery: a brief literature review. Multidiscip Respir Med. 2018;13:1-7.

3. D'Andrilli A, Maurizi G, Andreetti C, et al. Long-term results of laryngotracheal resection for benign stenosis from a series of 109 consecutive patients. Eur J Cardiothorac Surg. 2016;50(1):105-9.

4. Gaissert HA, Grillo HC, Wright CD, Donahue DM, Wain JC, Mathisen DJ. Complication of benign tracheobronchial strictures by self-expanding metal stents. J Thorac Cardiovasc Surg United States. 2003;126:744-7.

5. Freitas C, Martins N, Novais-Bastos H, Morais A, Fernandes G, Magalhães A. The role of interventional bronchoscopy in the management of postintubation tracheal stenosis: a 20-year experience. Pneumology. 2019;1045-1054.

6. Mehta AC, Lee FY, Cordasco EM, Kirby T, Eliachar I, De Boer G. Concentric tracheal and subglottic stenosis. Management using the Nd-YAG laser for mucosal sparing followed by gentle dilatation. Chest. 1993;104(3):673-7.

7. Wilkey BJ, Alfille P, Weitzel NSPF. Anesthesia for tracheobronchial surgery. Semin Cardiothorac Vasc Anesth. 2012;16:209-19.

8. Wiedemann KMC. Anesthesia and gas exchange in tracheal surgery. Thorac Surg Clin. 2014;24:13-25.

Publisher's Note Springer Nature remains neutral with regard to jurisdictional claims in published maps and institutional affiliations. 